\title{
A Profile of High Level Corporate Managers in the United States
}

\author{
Robin T. Peterson \\ College of Business Administration and Economics \\ New Mexico State University \\ Las C'ruces, New Mexico
}

\section{Introduction}

What are the backgrounds of the leaders of large and medium sized businesses in the United States? These individuals wield considerable power and influence. Their personality characteristics have been widely discussed by the popular press. Many television series depict top managers as highly educated men, who jump from one company to another, in pursuit of more desirable jobs. Are these and other beliefs about top managers mythical or do they approximate reality?

This paper presents the results of an inquiry into the characteristics, background, and behavior of the senior managers in large and medium sized United States business firms. Objective data on these variables should be of value in identifying and characterizing the top leaders and in suggesting vehicles which may have been responsible for their ascension to their current posts.

\section{Rationale}

It is apparent that there is need to analyze top managers' characteristics and background. Information on the characteristics of top managers is very useful in a macro sense, since the leadership that they provide is vitally significant to the well-being of the country at large. Top managers make decisions which affect the prosperity of the country, consumer satisfaction, and the state of the natural and cultural environment.

Another reason for studying the characteristics of top managers is to determine the extent to which they are a hornogeneous group. Are they part of an internally similar cluster, or do they come from diverse elements of society? Have affirmative action and related laws exerted an impact upon the makeup of this group? Such questions are difficult to answer, but data which provides clues to their resolution can be of substantial value.

This study was designed to provide some insights into the questions raised above and to other related issues.

Journal of Business Strategies, Volume 4, Number 2 (Fall 1987) 


\section{The Study}

\section{The Sample}

The sample consisted of 1,200 individuals who were C.E.O.'s or second or third level executives for firms with annual operating revenues of $\$ 50,000,000$ or more in 1985, and whose names appeared in the 1984-85 edition of Who's Who in America. Corporate directors were excluded, since many of them have been appointed to boards for outstanding achievement in fields other than business, such as the military, and might not fit the definition of business leaders. The sample was random and sequential.

The data were drawn from numerous industries, rather than being restricted to particular ones, such as some previous studies have. Further, the sample covered firms with sales above $\$ 50$ million, not just those listed in the Fortune 500. This was logical as the intention was to assume a relatively composite view, one that was not oriented to only the very largest firms. Top managers of concerns that are in the $\$ 50$ million or more range certainly exert an influence upon the economic and political fortunes of the United States, even if they are not encompassed in the Fortune 500. The rationale for this study, as outlined above, dictates that these "smaller" large companies be included in the sample.

\section{Collection of Data}

The data resulted from an examination of biographical entries in the 198485 edition of Who's Who in America. This source sets forth considerable information on the characteristics of over 75,000 biographees. The researcher randomly selected names of managers from this volume who were C.E.O.'s or second or third tier managers. The position of the individual in the organization and total annual operating revenues of the company in 1985 was then determined through reference to Moody's publications and annual reports. The managerial characteristics which were studied were those which Who's Who In America reports upon in a consistent and unambiguous fashion.

\section{Results on Personal Characteristics}

This section sets forth information on selected personal characteristics of the respondents.

The information contained in Who's Who In America is self-reported by the biographees, which means that it cannot be readily verified. However, the Who's Who staff makes a rigorous attempt to elicit accurate information and since the information is printed and widely disseminated, there is motivation for accurate self reporting.

\section{Gender}

The membership of the sample was overwhelmingly male. Of those enumerated, 1160 were men, 28 women, and 12 were not evident. Obviously, 
women have a long way to go if they are to gain anywhere near equal representation in the top executive positions. However, the results of this study do show a bit more female representation than do those of an inquiry into Fortune 500 top executives, taken by Sturdivant and Adler in 1975 [6]. In the 1975 study, none of the 444 executives analyzed were women ([6], p. 127). In another study of chief executive officers of large corporations, made in 1980, only one of 800 chief executives was a woman ([2], p. 50). Hence, the data in the present study might be taken as an indication of slightly more female participation.

The small numbers of women in top positions should not be viewed as evidence of the failure of equal opportunity efforts by industry or of women to achieve in business. Women only entered schools of business, engineering, and other professional fields in large numbers during the past decade and a half, are in the process of gaining experience and seniority, and more time must necessarily pass before they have advanced to the top positions in large concerns. After the passage of this time corporations will have available to them a new and expanding resevoir of executive talent.

\section{Age}

Table 1 outlines the frequencies of individuals occupying the top positions by age group. It also presents the age distribution of chief executive officers of large corporations, according to another study.

The bulk of the sample is in the 50-59 and 60-69 age groupings. The median figure is 55.8. This compares to a median of 57 in a 1976 study of Fortune 500 executives ([6], p. 176). The 1980 study referenced above listed a median of $55.2([2]$, p. 51). It appears that top managers are well into their years and that many are not far from retirement (although retirement at age 65 is often resisted by upper-echelon executives). In general, those who seek high-level positions may have to wait until they have accumulated considerable tenure, before they can acquire their target positions.

The age of the sample may help in explaining rationale for the charges of conservatism and lack of venturesomeness which are sometimes hurled at the United States business establishment [1]. Perhaps a younger cadre of senior executives might be more inclined to take risks and might extend its vision more into the long run impact of decision making. Firms such as Apple Computer, that are headed by younger managers often tend to be more inclined to absorb risk.

\section{Birthplace}

Table 2 sets forth the birthplaces reported by the sample. It is apparent that the Mid-Atlantic, East-North-Central, and West-North-Central regions account for the highest proportions of the total numbers. The last column sets forth total U.S. population in the various regions. In comparison to these, the Mid-Atlantic, East-North-Central, and West-North-Central areas produced more than their commensurate share of top executives, while the 
South-Atlantic, East-South-Central, West-South-Central, Mountain, and Pacific areas did not fare as well. It is apparent that the top executive group is clustered geographically (with almost sixty-five percent of the top executives in three regions).

Table 1

Age Distribution of the Sample

\begin{tabular}{|cccc|}
\hline $\begin{array}{c}\text { Age } \\
\text { Grouping }\end{array}$ & Frequency & Percentage & $\begin{array}{c}\text { Age Distribution } \\
\text { According to 1980 Study } \\
\text { Percentage }\end{array}$ \\
\hline $20-29.9$ & 12 & 1.0 & 0.6 \\
$30-39.9$ & 24 & 2.0 & 0.6 \\
$40-49.9$ & 172 & 14.3 & 11.6 \\
$50-59.9$ & 484 & 40.3 & 49.6 \\
$60-69.9$ & 404 & 33.7 & 35.0 \\
$70-79.9$ & 84 & 7.0 & 2.5 \\
$80 \&$ Over & 8 & 0.7 & 0.1 \\
Not Stated & 12 & 1.0 & 0.0 \\
\hline Totals & 1200 & 100.0 & 100.0 \\
\hline
\end{tabular}

aSOURCE: Louise Boone \& James C. Johnson, "Profiles of the 1980 Men and Women. at the Top." Business Horizons, February 1980, p. 51.

Table 2

Place of Birth of Sample Members

\begin{tabular}{|lccc|}
\hline \multicolumn{1}{|c}{ Birthplace } & Frequency & $\begin{array}{c}\text { Sample } \\
\text { Percentage }\end{array}$ & $\begin{array}{c}\text { U.S. Population } \\
\text { Percentage }^{a}\end{array}$ \\
\hline Northeast & 81 & 6.8 & 5.4 \\
Mid-Atlantic & 362 & 30.2 & 16.1 \\
South-Atlantic & 68 & 5.7 & 16.3 \\
East-South-Central & 44 & 3.7 & 6.4 \\
West-South-Central & 76 & 6.3 & 10.8 \\
East-North-Central & 269 & 22.4 & 18.0 \\
West-North-Central & 148 & 12.3 & 7.5 \\
Mountain & 21 & 1.7 & 5.2 \\
Pacific & 57 & 4.8 & 14.3 \\
Not Stated & 19 & 1.6 & N.A. \\
Foreign and Other & 15 & 1.3 & N.A. \\
\hline Totals & 1200 & 100.0 & 100.0 \\
\hline
\end{tabular}

aSOURCE: Statistical Abstract of the United States. Washington, DC: U.S. Government Printing Office, 1983, p. 12. 


\section{Number of Children}

Who's Who in America does not report on the marital status of its biographees. However, it contains a proxy variable on family status by indicating the number of children of each respondent. Table 3 contains the frequencies uncovered in the study. It indicates that most had two, three, or four children. These frequencies are typical for the United States at large ([5], p. 24), indicating that, at least with regard to number of children, the major executives do not differ significantly from the pattern of the average family.

Table 3

Number of Children Reported by the Sample Members

\begin{tabular}{|ccc|}
\hline $\begin{array}{c}\text { Number } \\
\text { of Children }\end{array}$ & Frequency & Percentage \\
\hline 0 & 55 & 4.6 \\
1 & 64 & 5.3 \\
2 & 357 & 29.8 \\
3 & 313 & 26.1 \\
4 & 220 & 18.3 \\
5 & 37 & 3.1 \\
6 & 28 & 2.3 \\
7 & 5 & 0.4 \\
8 & 3 & 0.3 \\
More than 8 & 2 & 0.2 \\
Not Stated & 116 & 9.7 \\
\hline Totals & 1200 & 100.0 \\
\hline
\end{tabular}

\section{Education}

Another set of variables relates to the levels and kinds of education which the top executives have attained. This section provides an examination of these.

\section{Degree Level}

Table 4 sets forth the classification of the respondents by degree level. The bulk of the group holds a bachelor's degree, although the portion who have completed a master's is approximately twenty percent of the total. In turn, those with doctorates account for close to sixteen percent of the total number. Compared to the population at large ([5], p. 134), this is very much a well educated group. Only about 3 percent of the sample had no degree. This compares with 4 percent in a 1976 study $([6]$, p. 130). 


\section{Table 4}

College Degree Level

of the Sample

\begin{tabular}{|lc|}
\hline \multicolumn{1}{|c|}{ Designation } & Percentage \\
\hline No College Degree & 3.2 \\
Bachelors Degree & 61.5 \\
Masters Degree & 19.6 \\
Doctorate Degree & 15.7 \\
\hline
\end{tabular}

\section{Public and Private Designation}

Another variable of interest is the extent to which the executive received their degrees from public or private colleges and universities. Of the 1,153 executives with degrees, 653 received them from private colleges and universities, 459 from public institutions, and 51 from institutions whose status could not be determined. This can be partially explained by the fact that many executives received their degrees prior to the mid 1950's, when private schools produced more graduates than their public counterparts.

\section{Year of Graduation}

Another variable of interest is the year in which the executives graduated from college. This indicates what cohort groups are now in power at the top. Table 5 furnishes the relevant statistics.

\section{Table 5}

Year in Which Respondents

Received College Degrees

\begin{tabular}{|ccc|}
\hline Year of Graduation & Frequency & Percentage \\
\hline $1920-1929$ & 12 & 1.0 \\
$1930-1939$ & 128 & 11.1 \\
$1940-1949$ & 331 & 28.7 \\
$1950-1959$ & 432 & 37.5 \\
$1960-1969$ & 175 & 15.2 \\
$1970-1979$ & 39 & 3.4 \\
$1980-1983$ & 5 & 0.4 \\
Not Stated & 31 & 2.7 \\
\hline Totals & 1153 & 100.0 \\
\hline
\end{tabular}

Most of the sample graduated during the 1950's. The second largest group received their degrees during the 1940's. They are followed by the 1960's and 1930's. Managers who graduated in the 1940's and 1950's tend to be relatively conservative in nature and are endowed with the work ethic [4]. As these individuals move out of power positions others with different values may replace them and transplant new cultures into the organizations which they 
lead. It should be expected that many of the values of the 1960's and 1970's will supplant those of the 1940's and 1950's over time.

\section{Degree Field}

Another variable of interest is the area in which the top executives received their degrees while in college. Table 6 presents the data from the study. By far the largest segment is made up of business administration, followed by law, engineering, and liberal arts. Most of the top managers, then, are from professional schools that provide a somewhat pragmatic educational background. The high concentration in business administration suggests that aspiring top executives should seriously consider a college in that field.

Table 6

Field in Which the Respondents

Received College Degrees

\begin{tabular}{|lcc|}
\hline \multicolumn{1}{|c}{ Field } & Frequency & Percent \\
\hline Business Admin. & 517 & 44.8 \\
Law & 196 & 16.9 \\
Engineering & 176 & 15.4 \\
Liberal Arts & 110 & 9.5 \\
Accounting & 60 & 5.2 \\
Economics & 22 & 1.9 \\
Other & 51 & 4.4 \\
Not Stated & 21 & 1.9 \\
\hline Totals & 1153 & 100.0 \\
\hline
\end{tabular}

\section{Work Experience}

The past work experience of the sample members provides some guidelines as to potential means of going to the top of an organization.

\section{Entry Position}

One key variable in this field is the entry level position which sample members occupied. Table 7 sets forth the results of the study on entry level. Unfortunately, many of the biographies did not report the nature of their entry level position. Of those which were enumerated, however, the largest is attorney, followed by manager, accountant, salesman, engineer, and trainee. These data may be somewhat misleading, as some individuals probably are well-established in their fields (such as an attorney) prior to joining their current employer. Other studies have indicated that the main background fields of high-level managers are finance, banking, administration and marketing $([3]$, p. 45).

Another characteristic is the number of employers the sample members have worked for in their careers (including the current employer). Table 8 indicates that the largest number of top executives had two employers. It would 
appear that loyalty to the organization has paid off for many who have made a minimum number of interemployer job moves. Another study [7], which indicates that well over one half of the top managers of large organizations have worked for only one employer during their careers, reinforces this finding.

Table 7

Entry Level Position of Sample Members

\begin{tabular}{|lcc|}
\hline \multicolumn{1}{|c}{ Position } & Frequency & Percent \\
\hline Attorney & 91 & 7.6 \\
Manager & 80 & 6.6 \\
Accountant & 73 & 6.1 \\
Salesman & 69 & 5.8 \\
Engineer & 68 & 5.7 \\
Trainee & 27 & 2.2 \\
Other & 156 & 13.0 \\
Not Stated & 636 & 53.0 \\
\hline Number of Employers & 1200 & 100.0 \\
\hline
\end{tabular}

Table 8

Number of Employers

of the Sample Members

\begin{tabular}{|ccc|}
\hline $\begin{array}{c}\text { Number } \\
\text { of Employers }\end{array}$ & Frequency & Percent \\
\hline 1 & 202 & 16.8 \\
2 & 306 & 25.5 \\
3 & 193 & 16.1 \\
4 & 191 & 15.9 \\
5 & 112 & 9.3 \\
6 & 96 & 8.0 \\
7 & 31 & 2.6 \\
8 & 20 & 1.7 \\
9 & 9 & 0.8 \\
10 & 4 & 0.3 \\
Over 10 & 7 & 0.6 \\
Not Stated & 29 & 2.4 \\
\hline Totals & 1200 & 100.0 \\
\hline
\end{tabular}

Number of Jobs with Present Company

The research involved tabulating the number of jobs that the sample members had held with their present company. Table 9 presents the results.

The highest frequencies are associated with two, one, and four positions. The typical top executive, then, has held several jobs with the firm. On the 
other hand, a smaller number of executives have held many positions with the same enterprise as they progress upward in the hierarchy.

Table $\theta$

Number of Positions Held

with Current Employer

\begin{tabular}{|ccc|}
\hline $\begin{array}{c}\text { Number of } \\
\text { Positions }\end{array}$ & Frequency & Percent \\
\hline 1 & 313 & 26.1 \\
2 & 355 & 29.6 \\
3 & 197 & 16.4 \\
4 & 133 & 11.1 \\
5 & 51 & 4.3 \\
6 & 69 & 5.7 \\
7 & 25 & 2.1 \\
8 & 27 & 2.2 \\
9 & 4 & 0.3 \\
10 & 8 & 0.7 \\
More Than 10 & 5 & 0.4 \\
Not Stated & 13 & 1.1 \\
\hline Totals & 1200 & 100.0 \\
\hline
\end{tabular}

\section{Number of Jobs with Other Companies}

Another variable enumerated was the number of executive level jobs the sample members had held with other firms. Table 10 specifies the frequencies.

The bulk of the respondents have not held executive level jobs with other firms. Of those who have, the highest frequencies are associated with one, two, and three positions. It would not appear, based upon these frequencies, and those in Table 8 the sample members made their way to their present jobs through frequent job-hopping from one organization to another. Rather, tenure with a single company seems to be an excellent means of progressing to the top.

\section{Military Service}

The bulk of the sample-702 respondents-had served in the military at some time in the past. On the other hand, 303 respondents had not served. The remainder-195 respondents-did not state if they had served or not. Of those who were in the service, 229-about a total of one third-were officers. The others were enlisted personnel or did not state their rank. In the population at large approximately $40 \%$ of those over age 21 are veterans ([5], pp. 24; 346). Thus the percentage of top business leaders who are veterans is larger than that for the population in general. 


\section{Affiliations}

There are a number of affiliations of sample members which give clues to their past history.

\section{Political Party}

Of the total sample, $479(39.9 \%)$ indicated that they were Republicans and $124(10.3 \%)$ that they were Democrats. The remainder, $597(49.8 \%)$, did not state a political party affiliation. It would appear that many of the executives are either independent or do not have a strong enough political preference to set it forth in Who's Who. Of those who cite a preference the ratio is almost four to one in favor of the Republicans. According to survey data the number of adults in the general population who were registered Democrats substantially exceeded the number of registered Republicans in 1985 ([5], p. 149).

Table 10

Number of Executive Level Jobs Held with Other Companies

\begin{tabular}{|ccc|}
\hline $\begin{array}{c}\text { Number } \\
\text { of Jobs }\end{array}$ & Frequency & Percent \\
\hline 0 & 585 & 48.7 \\
1 & 174 & 14.5 \\
2 & 136 & 11.2 \\
3 & 80 & 6.7 \\
4 & 47 & 3.9 \\
5 & 57 & 4.8 \\
6 & 36 & 3.0 \\
7 & 33 & 2.8 \\
8 & 11 & 0.9 \\
9 & 9 & 0.8 \\
10 & 24 & 2.0 \\
Over 10 & 7 & 0.6 \\
Not Stated & 1 & 0.1 \\
\hline Totals & 1200 & 100.0 \\
\hline
\end{tabular}

\section{Religious Preference}

Table 11 reports on the religious preferences of the sample members. Most did not cite their religious preference. Of those who did, the leading denominations are Presbyterian, Episcopalian, and Roman Catholic. The number of top managers who embrace the Jewish religion stated as a percentage of the total population who embrace the religion is slightly higher than the similar percentage for the Protestant religion. The percentage for Protestants is three times larger than that for those who are Roman Catholic [8]. 
Table 11

Religious Preferences

of Sample Members

\begin{tabular}{|lrr|}
\hline \multicolumn{1}{|c}{ Religion } & Frequency & Percent \\
\hline Presbyterian & 120 & 10.0 \\
Methodist & 61 & 5.1 \\
Roman Catholic & 72 & 6.0 \\
Baptist & 23 & 1.9 \\
Episcopalian & 84 & 7.0 \\
Jewish & 37 & 3.1 \\
Church of Christ & 8 & 0.7 \\
Mormon & 23 & 1.9 \\
Other & 108 & 9.0 \\
Not Stated & 664 & 55.3 \\
\hline Totals & 1200 & 100.0 \\
\hline
\end{tabular}

National Associations

The number of national organizations of which the respondents were members was tabulated. Table 12 furnishes the results. Memberships for most executives are in the range of one to four organizations, although some report many more. The data suggest that on average, top executives do not seek membership in numerous national associations. Multiple memberships may not be a requisite for the upward-bound.

Table 12

Number of Memberships Reported in National Associations

\begin{tabular}{|ccc|}
\hline $\begin{array}{c}\text { Number of } \\
\text { Associations }\end{array}$ & Frequency & Percent \\
\hline 1 & 263 & 21.9 \\
2 & 225 & 18.8 \\
3 & 140 & 11.7 \\
4 & 127 & 10.6 \\
5 & 77 & 6.4 \\
6 & 19 & 1.6 \\
7 & 9 & 0.8 \\
8 & 24 & 2.0 \\
9 & 5 & 0.4 \\
10 & 15 & 1.2 \\
Over 10 & 21 & 1.8 \\
Not Stated & 275 & 22.8 \\
\hline Totals & 1200 & 100.0 \\
\hline
\end{tabular}


Finally, the study tabulated the number of memberships in regional or local organizations. Table 13 presents the data.

Table 13

Memberships in Regional

or Local Organizations

\begin{tabular}{|ccc|}
\hline $\begin{array}{c}\text { Number of } \\
\text { Memberships }\end{array}$ & Frequency & Percent \\
\hline 1 & 267 & 22.3 \\
2 & 165 & 13.8 \\
3 & 64 & 5.3 \\
4 & 25 & 2.1 \\
5 & 3 & 0.2 \\
6 & 32 & 2.7 \\
7 & 0 & 0.0 \\
8 & 4 & 3.3 \\
9 & 0 & 0.0 \\
10 & 0 & 0.0 \\
Over 10 & 0 & 0.0 \\
Not Stated & 640 & 50.3 \\
\hline Totals & 1200 & 100.0 \\
\hline
\end{tabular}

The largest frequency is not stated, indicating that the biographies probably did not perceive local memberships to be of extreme importance, so that they would be listed in the publication. Beyond "not stated" the highest frequencies are with one, two and three organizations, in that order. As in the case of national organizations, multiple memberships appear not to be highly sought-after.

\section{Summary and Conclusion}

A summary view of the accumulated information from the study permits the formulation of a composite picture of typical top executives. They are mainly men, age 50-70 who were born in the Mid-Atlantic and East-NorthCentral regions. The bulk of these individuals have $2-4$ children. They have a bachelors degree from a private institution, which they received in the 1940's or 1950 's, probably in business administration. They entered their professional careers as an attorney or manager trainee and have had less than three employers and only one or two positions with their current employer. They have military experience and are either not affiliated with a political party or are Republicans. Of those who state their religious affiliation the largest numbers are Presbyterian, Episcopalian or Roman Catholic, many biographees report belonging to a small number of national or regional and local organizations. 
Finally, the findings indicate that top executives manifest substantial similarities in some respects, such as sex, age, number of children, and education, but certainly do not make up a homogeneous group. There are major differences within the group with respect to birthplace, public versus private college education, entry position, number of past positions held, and religious affiliation. Top executives are similar in many ways but also exhibit numerous differences.

\section{References}

1. Bachholz, Rogene A. "An Empirical Study of Contemporary Beliefs About Work in American Society." Journal of Applied Psychology, vol. 63, 1978, pp. 219-228.

2. Boone, Louis E., and Johnson, James C. "Profiles of the 801 Men and 1 Woman at the Top." Business Horizons, February 1980, p. 50.

3. Fleenor, G. Patrick, David Likurtz, and Louis E. Boone. "The Changing Role of Business Leadership." Business Horizons, July/August 1983, p. 45.

4. Sharp, Laure M. Education and Employment, Baltimore: The Johns Hopkins Press, 1970, pp. 77-82.

5. Statistical Abstract of the United States, Washington, D.C. U.S. Government Printing Office, 1986, p. 24.

6. Sturdivant, Frederick D., and Adler, Roy. "Executive Origins: Still a Gray Flannel World?" Harvard Business Review, November/December 1976 , p. 127.

7. Tuckel, Peter, and Siegel, Karolynn. "The Myth of the Migrant Manager." Business Horizons, January/February 1983, pp. 65-67.

8. "Voter Registrations." Opinion Roundup, January/February 1987, pp. 23 \& 24. 